\section{Conclusion}

There does seem to be sufficient evidence to conclude that as dementia advances with age, patients who speak two or more languages have a tendency to revert to their primary language. It does also appear that bilingual and multilingual immigrants from various geographical backgrounds appear to be protected from the onset of dementia for about 4 years. In terms of the National Dementia Strategy referred to above, these linguistic issues are important in the treatment of aphasic bilingual or multilingual patients. If we are to provide information and make people aware of the implications of their illness, further research is necessary which could lead to improved communication and care for these patients suffering from dementia who belong to ethnic minorities.

\section{References}

Ardila, A. \& Ramos, E. (2010) Bilingualism and aging. Perspectives on Communication Disorders and Sciences in Culturally and Linguistically Diverse Populations, 17, 74-81.

Bialystok, E., Craik, F. I. \& Freedman, M. (2006) Bilingualism as a protection against the onset of symptoms of dementia. Neuropsychologia, 42, 459-464.
D'Acierno, M. R. (1990) Three Types of Bilingualism. Educational Resources Information Centre (ERIC). At http://www.eric.ed.gov:80/PDFS/ ED321574.pdf (accessed 3 June 2011).

Diaz, C. \& Peraita, H. (2008) Neuropsychological evaluation and cognitive evolution of a bilingual Alzheimer patient. Revista de Psicopatología y Psicología Clínica, 13, 219-228.

Fabbro, F. (2002) The bilingual brain: cerebral representation of languages. Brain and Language, 79, 211-222.

Hendrie, H. C., Ogunniyi, A., Hall, K. S., et al (2001) Incidence of dementia and Alzheimer disease in 2 communities: Yoruba residing in Ibadan, Nigeria, and African Americans residing in Indianapolis, Indiana. JAMA, 285, 739-747.

Howard, C. (2010) Multilingualism (but not always bilingualism) delays the onset of Alzheimer disease: evidence from a bilingual community. Alzheimer Disease and Associated Disorders, 24, 118-125.

Hyltenstam, K. \& Obler, L. K. (1989) Bilingualism Across the Lifespan: Aspects of Acquisition, Maturity, and Loss. Cambridge University Press.

Mendez, M. F., Perryman, K. M., Pontoon, M. O., et al (1999) Bilingualism and dementia. (Letter.) Journal of Neuropsychiatry and Clinical Neurosciences, 11, 411-412.

Paradis, M. (1997) The Assessment of Bilingual Aphasia. Lawrence Erlbaum.

Perani, D., Paulesu, E., Galles, S. B., et al (1998) The bilingual brain proficiency and age of acquisition of second language. Brain, 121, 1841-1852.

Wattendorf, E. \& Festman, J. (2008) Images of the multilingual brain: the effect of age of second language acquisition. Annual Review of Applied Linguistics, 28, 3-24.

\title{
Psychiatrists are stakeholders in improving access to controlled medicines
}

\section{Willem Scholten PharmD MPA}

Team Leader, Access to Controlled Medicines, Department of Essential Medicines and Pharmaceutical Policies, World Health Organization, Geneva, Switzerland, email ScholtenW@who.int

M edicines made from substances that are controlled under the international drug control treaties ('controlled medicines') are out of reach for the majority of patients around the world. Seya et al (2011) demonstrated that 5.5 billion people ( $83 \%$ of the world's population) live in countries with little or no access to opioid analgesics, 250 million (4\%) have moderate access and only 460 million people (7\%) have adequate access. Insufficient data are available for 430 million (7\%). If the need for treatment of moderate to severe pain were to be satisfied adequately, the global consumption of strong opioid analgesics would go up from 231 tonnes of morphineequivalents to 1292 tonnes.

Controlled medicines belong to a number of therapeutic classes. The World Health Organization (WHO) has produced a Model List of Essential Medicines and a Model List of Essential Medicines for Children. Among the controlled medicines on these lists are: opioid analgesics; long-acting opioids for the treatment of opioid dependence; medicines for emergency obstetrics; benzodiazepines both for mental disorders and against epilepsy; and phenobarbital, also an anti-epileptic. Ketamine is listed as an 
anaesthetic and, although not controlled under the international treaties, many countries now control it under their national responsibility. Ketamine is often the only possibility for anaesthesia in resource-poor, often rural settings in low- and middle-income countries. Various other medicines not listed on the WHO Model Lists of Essential Medicines are controlled, including stimulants for the treatment of attention-deficit hyperactivity disorder (ADHD) and similar syndromes.

For classes other than opioid analgesics, we have limited data on their availability. However, it is certain that many do not have access to opioids for the treatment of opioid dependence. Furthermore, it has been reported that in lowand middle-income countries many patients with epilepsy are not treated and are thus needlessly disabled. In Africa, $80 \%$ of the population affected by epilepsy have no access to essential anti-epileptic medicines (World Health Organization, 2008). With benzodiazepines we estimate that under- and over-treatment occur simultaneously, but whether over- or under-treatment dominates depends very much on the country situation.

During the past century the world has developed an international system of drugs control that has gradually become more stringent. The current treaties date back to 1961 (amended by a protocol in 1972) and 1971. After stating that the parties are 'concerned with the health and welfare of mankind', the treaties define the objectives of the prevention of 'abuse' and dependence, and of keeping the controlled medicines available for medical and scientific purposes. However, the focus over time has been on the prevention of misuse and dependence, so much so that the accessibility and availability of the medicines containing the substances have declined.

Legislation in many countries does not allow for the medical use of these medicines; even where it is allowed, procedures are complex and in practice patients often do not have access. Also, many physicians do not have adequate knowledge of how to use these substances and many are biased against their use because they believe patients will become very easily dependent on these medicines when prescribed, or even will be killed by their medicines. Patients and their families often hold similar attitudes and hence many refuse potentially beneficial treatments. Moreover, procurement can be difficult because of the bureaucracy involved and low turn-over expectations may hamper enterprises seeking market access for these medicines.

\section{WHO action towards better patient access}

Since 1986, the International Narcotics Control Board (INCB) has requested that countries improve access to controlled medicines. For instance, in its 2009 annual report, it once again declared that:

One of the fundamental objectives of the international drug control treaties is to ensure the availability of narcotic drugs and psychotropic substances for medical and scientific purposes and to promote access to and rational use of narcotic drugs and psychotropic substances. (United Nations, 2010)
Over the last few years, attention to the problem of low accessibility has increased, as shown by resolutions adopted by the World Health Assembly (World Health Organization, 2005), the United Nations Economic and Social Council (United Nations, 2005) and the Commission on Narcotic Drugs (2010). As a result of the former two resolutions, the INCB and WHO developed the Access to Controlled Medications Programme in 2007, operated by the WHO. Many other organisations have developed activities to improve access to these medicines. Human Rights Watch (2009) and the Open Society Institute (2008) have published on the topic.

The WHO's Ensuring Balance in National Policies on Controlled Substances provides guidance on how to develop policy and legislation that will improve access to these medicines (World Health Organization, 2011). It includes 21 guidelines based on the principle of balance, i.e. that policies should aim to optimise public health outcomes by maximising access to controlled medicines for medical and scientific purposes while minimising misuse and dependence. The guidance, which includes a Country Assessment Checklist for operationalising its recommendations, can be used by governments and others to review policies and legislation.

Over the years, the WHO Access to Controlled Medications Programme experienced a tendency to focus on pain patients and even on cancer pain patients only. However, the WHO estimates that there are, in addition to the 5.5 million cancer pain patients untreated for pain every year, tens of millions other pain patients who are not treated for their moderate or severe pain. Moreover, it is estimated that 1 million HIV infections could be prevented every year if methadone and/ or buprenorphine were available for the treatment of dependence and annually 75000 cases of maternal death from post-partum haemorrhage could be prevented if ergometrine (which is also a precursor for LSD) or oxytocin (not under international control) were readily available (World Health Organization, 2009). Benzodiazepines, although they may be over-prescribed in some countries, may be insufficiently available in other countries. Causes of the unavailability of controlled medicines may be similar for all these classes of medicine and therefore it is important that any action taken to improve access to and the availability of controlled medicines aims at all of these medicines.

\section{Prescription medicines}

A new threat to patients' access to these medicines is the misuse of prescription medicines. Often little distinction is made between prescription and prescribed medicines, between medicines legally distributed through pharmacies and medicines sold illicitly through the internet, counterfeit medicines or medicines obtained from crime. Many research publications on this topic do not define their sample population well, but a review that did so demonstrated very low figures for misuse of $(0.25 \%)$ and dependence on $(0.05 \%)$ opioids prescribed for pain treatment (Noble et al, 2008).

Misuse of prescription medicines is a problem in some countries, but more detailed information on the source of the medicines and the mechanisms behind their diversion is urgently needed. This is crucial in order to avoid the implementation of ineffective measures that only deny patient access to these essential medicines. 


\section{Conclusion}

Psychiatrists all around the world have various stakes in controlled medicines. They have an urgent need to be able to prescribe methadone or buprenorphine for the evidencebased treatment of dependence and to use benzodiazepines for various other mental disorders. In collaboration with organisations of other medical specialists, their national associations should advocate improved access to these medicines. Furthermore, they can play a role in monitoring misuse of and dependence on these medicines when prescribing them and in collecting information on the mechanisms behind the diversion and misuse of prescription medicines.

These associations can, together with those of other medical specialties and patients' organisations, assess the situation with regard to controlled medicines in their country by using the recent WHO policy guidelines and the checklist mentioned above. Together they can call on governments to implement policies and legislation aimed at solving any problems identified and can promote attitudes and practices among their members that will help to overcome such problems.

\section{References}

Commission on Narcotic Drugs (2010) Resolution 53/4: Promoting adequate availability of internationally controlled licit drugs for medical and scientific purposes while preventing their diversion and abuse. Tenth plenary meeting. At http://www.unodc.org/documents/ commissions/CND-Res-2000-until-present/CND53_4e.pdf (accessed 4 January 2011).

Human Rights Watch (2009) Please, Do Not Make Us Suffer Any More... Access to Pain Treatment as a Human Right. Human Rights Watch. At http://www.hrw.org/sites/default/files/reports/health0309web_1.pdf (accessed 8 February 2011).

Noble, M., Tregear, S. J., Treadwell, J. R., et al (2008) Long-term opioid therapy for chronic non-cancer pain: a systematic review and meta-analysis of efficacy and safety. Journal of Pain and Symptom Management, 35, 214-228.

Open Society Institute (2008) Harm Reduction Developments 2008. Countries with Injection-Driven HIV Epidemics. At http://www.soros. org/initiatives/health/focus/ihrd/articles publications/publications/ developments_20080304/developments_20080304.pdf (accessed 8 February 2011).

Seya, M. J., Gelders, S. F. A. M., Achara, O. U., et al (2011) A first comparison between the consumption of and the need for opioid analgesics at country, regional and global level. Journal of Pain and Palliative Care Pharmacotherapy, 25, 6-18.

United Nations (2005) Resolution ECOSOC 2005/25. Treatment of pain using opioid analgesics. Thirty-sixth plenary meeting. At http://www. un.org/docs/ecosoc/documents/2005/resolutions/Resolution $\% 20$ 2005-25.pdf (accessed 5 January 2011).

United Nations (2010) Report of the International Narcotics Control Board for 2009. Paragraph 789. UN. At http://www.incb.org/pdf/ annual-report/2009/en/AR_09_English.pdf (accessed 5 January 2011).

World Health Organization (2005) Resolution WHA 58.22. Cancer prevention and control. World Health Assembly 58. At http://www.who. int/ipcs/publications/wha/cancer_resolution.pdf (assessed 5 January 2011).

World Health Organization (2008) Scaling Up Care for Mental, Neurological, and Substance Use Disorders. Mental Health Gap Action Programme. WHO. At http://whqlibdoc.who.int/ publications/2008/9789241596206_eng.pdf (accessed 5 January 2011).

World Health Organization (2009) Access to Controlled Medications Programme: improving access to medications under international drug conventions. Briefing note. WHO. At http://www.who.int/medicines/ areas/quality_safety/ACMP_BrNoteGenrl_EN_Feb09.pdf (accessed 5 January 2011).

World Health Organization (2011) Ensuring Balance in National Policies on Controlled Substances: Guidance for Accessibility and Availability for Controlled Medicines. WHO.

\section{College position statement: recommendations for psychiatrists on spirituality and religion}

Evidence suggests that the relationship between spirituality/ religion and mental health is a positive one, and there may be benefits associated with considering spiritual and religious factors within treatment planning. The Royal College of Psychiatrists' position statement recommends that psychiatrists consider a tactful and sensitive exploration of patients' religious beliefs and spirituality during consultations - but that psychiatrists should also ensure that a patient's lack of religious or spiritual beliefs is equally respected. The statement can be viewed on the College's website (http://www. rcpsych.ac.uk/publications/collegereports/positionstatements. aspx).

\section{Inayat Khan}

The World Health Organization has highlighted on its website the achievements of a former member of staff, Dr Inayat Khan, who is also a Fellow of the College (see http://www.who.int/archives/fonds_collections/special/ former_staff_history_khan/en/index.html).

\section{Obituary - Professor Tolani Asuni}

The College is saddened to announce the death of Professor Tolani Asuni on 21 June 2011 at age 86 in Lagos. Professor Asuni was a Foundation Fellow of the Royal College of Psychiatrists and had a long, illustrious professional career in Nigeria at Obufemi Awolowo in Lagos, Ibadan University and the Federal Neuropsychiatric Hospital Abeokuta. He was one of the founders, and the first President, of the Association 